\title{
The evaluation of markers of prostatic inflammation and function of the prostate gland in patients with chronic prostatitis
}

\author{
Bożena Zdrodowska-Stefanow ${ }^{1}$, Iwona Ostaszewska-Puchalska², Jerzy Badyda ${ }^{3}$ \\ and Zofia Galewska ${ }^{4}$
}

${ }^{1}$ Department of Dermatology and Venerology, Medical University, Białystok, Poland

2 Center for Sexually Transmitted Diseases Research and Diagnostics, Białystok, Poland

3 Outpatient Urology Clinic "Multimedica", Białystok, Poland

${ }^{4}$ Department of Medical Biochemistry, Medical University, Białystok, Poland

Received: 2007.09.25, Accepted: 2008.06.30, Published online first: 2008.07.29

\begin{abstract}
Introduction: The aim of the study was to determine the numbers of polymorphonuclear (PMN) leukocytes and PMN elastase and citric acid concentrations in chronic prostatitis patients regardless of etiology and in those with Chlamydia trachomatis infection of the prostate gland.

Materials and Methods: The study involved 46 patients with chronic prostatitis. Expressed prostatitc secretions (EPS) were obtained to determine the leukocyte count, PMN elastase (ELISA) and citric acid concentrations (UV method), and the occurrence of $C$. trachomatis infection (ligase chain reaction).

Results: Increased PMN cell counts ( $\geq 10$ per high-power field) were found in $73.9 \%$ of patients and increased PMN elastase concentration $(<250 \mathrm{ng} / \mathrm{ml})$ in $78.3 \%$. In $44.4 \%$ of the patients the elastase concentration indicated moderate $(250-1000$ $\mathrm{ng} / \mathrm{ml})$ and in $55.6 \%$ acute infection $(\geq 1000 \mathrm{ng} / \mathrm{ml})$. Decreased citric acid concentration $(<18.12 \mathrm{mg} / \mathrm{ml})$ in the EPS was found in $65.2 \%$ of the men. C. trachomatis prostate infection was detected in $17.4 \%$ of the patients and all of these men had higher inflammation parameters and lower citric acid concentrations.

Conclusions: $C$. trachomatis prostate inflammation was accompanied by an increase in inflammation markers and a decrease in citric acid concentration.

Key words: chronic prostatitis, Chlamydia trachomatis, citric acid, prostate gland, expressed prostatic secretions, PMN elastase.

Corresponding author: Iwona Ostaszewska-Puchalska, Ph.D. M.D., Center for Sexually Transmitted Diseases Research and Diagnostics, Św. Rocha 3, 15-879 Białystok, Poland, tel.: +48 85 746-04-54, fax: +48 85 742-36-30, e-mail: centstd@ poczta.onet.pl
\end{abstract}

\section{INTRODUCTION}

Chronic prostatitis is one of the most common urological diseases in men [1]. According to the latest classification by the National Institutes of Health (NIH), this type belongs to group III of the so-called chronic prostatitis/chronic pelvic pain syndrome (CP/CPPS) [15]. Chlamydia trachomatis (C. trachomatis) is a sexually transmitted intracellular microorganism which can survive in the human organism for several years in a state of latency. It is an etiologic factor of prostatitis $[3,19]$. Chlamydial prostatitis was formerly included in group III of the NIH classification [12]. Currently it is frequently placed in group II (so-called chronic bacterial prostatitis - CBP) [20].
Polymorphonuclear (PMN) leukocyte count is thought to be the main marker of inflammation in the genitourinary tract. It is usually determined in urethral swabs, expressed prostatic secretions (EPS), semen, or urinary sediment $[18,21]$. PMN elastase, secreted by PMN leukocytes, is also a sensitive indicator of inflammation [28]. Its importance in detecting latent genitourinary inflammation in men has been described in recent literature [29].

The concentration of citric acid is a significant parameter of prostate gland function [11]. Substantial amounts of citric acid are produced and stored in the gland [7]. A decrease in its concentration is observed in cases of inflammation or cancer of the prostate gland $[2,10]$. 
The aim of this study was to assess the occurrence of inflammation markers and citric acid levels in patients with chronic prostatitis (CP/CPPS or/and CBP) irrespective of etiology. The study was also conducted to evaluate the relationship of $C$. trachomatis infection with the parameters of prostate inflammation and function.

\section{MATERIALS AND METHODS}

The study involved 46 men ranging in age from 16 to 73 years old (average: 40 years) with chronic prostatitis (CP/CPPS and/or CBP). All patients were referred to the Center for Sexually Transmitted Diseases Research and Diagnostics in Białystok from urological outpatient departments. All the patients were enrolled into the study based on clinical symptoms of the genitourinary tract lasting more than 3 months. Each patient completed the NIH-CPSI questionnaire. This includes 9 questions concerning pain or discomfort (4 questions), problems with urination (2 questions), and the impact of symptoms on everyday life and quality of life (3 questions). The score indirectly indicates the severity of symptoms. None of the patients received antibiotics for at least three months preceding the study. Based on urinalysis and bacteriological tests (from the mid-stream), only patients with negative leukocyturia and bacteruria were included, excluding those with bladder inflammation.

Urethral smears as well as EPS served as the material. C. trachomatis infection was detected in the urethral smears. Expressed prostatic secretions were used as the material to determine the PMN leukocyte count, the concentrations of PMN elastase and citric acid, and C. trachomatis infection. Direct preparations were performed on microscopic slides using the first drop of prostatic fluid. After fixing and staining by Gram's method, the leukocytes were counted in the smears [8]. Prostatitis was diagnosed at $\geq 10$ PMN cells per highpower field (hpf; $\times 1000)[4,14,18]$. Values $\geq 10 \mathrm{PMN}$ cells per hpf were regarded as elevated leukocyte counts.

The remaining EPS were used to determine the concentrations of PMN elastase and citric acid and to detect C. trachomatis infection. An immunoenzymatic method (PMN - elastase ELISA, version 2 h, Merck, Germany) described by Wolff and Andersen [22] was used to determine granulocyte elastase concentrations. The PMN elastase results were interpreted by applying the Jochum et al. [9] classification, i.e. $<250 \mathrm{ng} / \mathrm{ml}$ is considered no inflammation, $250-1000 \mathrm{ng} / \mathrm{ml}$ moderate inflammation, and $\geq 1000 \mathrm{ng} / \mathrm{ml}$ acute inflammation. Values $<250 \mathrm{ng} / \mathrm{ml}$ were regarded as decreased elastase levels. The concentrations of citric acid were measured at the Department of Medical Biochemistry of the Medical University of Białystok using the ultraviolet method (TC Citric Acid, Boehringer) [25]. We considered $18.84 \pm 0.72 \mathrm{mg} / \mathrm{ml}(18.12-19.59 \mathrm{mg} / \mathrm{ml})$ as the stan- dard [6], 12.01-18.11 $\mathrm{mg} / \mathrm{ml}$ as a small decrease, $7.01-12.0 \mathrm{mg} / \mathrm{ml}$ a moderate decrease, and $\leq 7.0 \mathrm{mg} / \mathrm{ml}$ a high decrease. The LCx STD Swab Specimen Collection System was used to collect prostatic fluid for the detection of $C$. trachomatis infection. A previously described [16] ligase chain reaction test (LCx, Abbott, USA) was used to detect $C$. trachomatis infection.

Statistical analysis was performed using the Mann-Whitney test, Fisher's exact test, Spearman's correlation coefficient, and ROC curve analysis. Differences were considered statistically significant when $\mathrm{p}$ was less than or equal to 0.05 .

This study was approved by the University Ethics Committee.

\section{RESULTS}

Inflammation of the prostate determined by a high PMN cell count in the prostatic fluid was diagnosed in $34 / 46(73.9 \%)$ of the men studied. The most frequent, i.e. in $28 / 34(82.4 \%)$ patients, was 10-20 leukocytes per hpf. Two patients had 21-30 PMN cells per hpf and four had over 30.

We observed an increased concentration of granulocyte elastase in $36 / 46(78.3 \%)$ patients. In 16/36 (44.4\%) men the PMN elastase concentration indicated moderate infection $(250-1000 \mathrm{ng} / \mathrm{ml})$ and in 20/36 (55.6\%) cases acute infection $(>1000 \mathrm{ng} / \mathrm{ml})$. In four patients whose results indicated an acute infection the elastase concentration reached $>10,000 \mathrm{ng} / \mathrm{ml}$. A high co-occurrence $(40 / 46,87 \%)$ of the inflammation markers in the EPS was observed. Only in 6/46 (13\%) patients were some discrepancies revealed. In four cases, PMN elastase concentration was elevated, but with a lack of leukocytes. Two patients had higher PMN cell counts with no increase in elastase concentration. A significant positive Spearman's correlation $(p=0.000001)$ was found between increased leukocyte count ( $>10$ per hpf) and elevated PMN elastase level in EPS $(r=0.66)$. Table 1 presents all concentrations of the inflammation markers in the EPS in the study group. In four patients with high leukocyte counts (>30 per hpf) in the EPS we observed high granulocyte elastase concentrations (in two of the men exceeding $10,000 \mathrm{ng} / \mathrm{ml}$ ).

Table 1. Inflammation marker test results in the EPS of chronic prostatitis patients $(n=46)$

\begin{tabular}{|c|c|c|c|c|c|}
\hline \multirow{2}{*}{$\begin{array}{l}\text { PMN-elastase } \\
(\mathrm{ng} / \mathrm{ml})\end{array}$} & \multicolumn{4}{|c|}{ PMN cells per hpf } & \multirow{2}{*}{ Tota } \\
\hline & negative & $10-20$ & $21-30$ & $>30$ & \\
\hline Negative $(<250)$ & 8 & 2 & 0 & 0 & 10 \\
\hline $\begin{array}{l}\text { Intermediate } \\
\text { positive } \\
(250-1000)\end{array}$ & 4 & 10 & 2 & 0 & 16 \\
\hline $\begin{array}{l}\text { High positive } \\
(>1000)\end{array}$ & 0 & 16 & 0 & 4 & 20 \\
\hline Total & 12 & 28 & 2 & 4 & 46 \\
\hline
\end{tabular}


Table 2. Citric acid concentrations and polymorphonuclear leukocyte counts in the EPS of chronic prostatitis patients $(\mathrm{n}=46)$

\begin{tabular}{lrrrrr}
\hline \multirow{2}{*}{$\begin{array}{c}\text { Concentration } \\
\text { of citric acid } \\
\quad(\mathrm{mg} / \mathrm{ml})\end{array}$} & \multicolumn{4}{c}{ PMN cells per hpf } & \\
\cline { 2 - 5 } & negative & $10-20$ & $21-30$ & $>30$ & Total \\
\hline Normal $^{*}$ & 10 & 6 & 0 & 0 & 16 \\
Low decrease $^{* *}$ & 2 & 18 & 2 & 0 & 22 \\
$\begin{array}{l}\text { Intermediate } \\
\text { decrease }\end{array}$ & 0 & 4 & 0 & 0 & 4 \\
$\begin{array}{l}\text { High decrease } \\
\text { Total }\end{array}$ & 0 & 0 & 0 & 4 & 4 \\
\hline
\end{tabular}

* $>18.11 \mathrm{mg} / \mathrm{ml}$, ** $12.01-18.11 \mathrm{mg} / \mathrm{ml}$, *** $7.01-12.0 \mathrm{mg} / \mathrm{ml}$, $* * * *<7.0 \mathrm{mg} / \mathrm{ml}$.

A decrease in the concentration of citric acid in the EPS was found in 30/46 (65.2\%) men. In this group of 30 the leukocyte count was increased in 28 (93.3\%), whereas 26 of the $30(86.7 \%)$ had higher concentrations of PMN elastase in the EPS. Table 2 presents the results of citric acid concentration and leukocyte count in the EPS. A significant negative Spearman's correlation $(\mathrm{p}=0.00003)$ was noted between increased leukocyte count ( $>10$ per hpf) and decreased citric acid level in the EPS $(r=0.58)$. In most of the patients $(18 / 28,64.3 \%)$ with a slightly elevated leukocyte count (10-20 per hpf), a minor decline was observed in the concentration of citric acid. In all the men with a high leukocyte count in the EPS ( $>30$ per hpf), a significant decrease was noted in the concentration of citric acid. Table 3 shows the concentrations of citric acid and PMN elastase in EPS. A significant negative Spearman's correlation $(p=0.009)$ was observed between elevated PMN elastase level and reduced citric acid concentration in EPS $(\mathrm{r}=0.38)$.

In this study, $C$. trachomatis infection in EPS was found in 8/46 (17.4\%) men. Urethral chlamydial infection was not confirmed in any of the patients. All of the men with chlamydial infection of the prostate gland had increased concentrations of PMN elastase and leukocyte counts and decreased concentrations of citric acid in EPS. The levels of the inflammation markers (PMN > 30 per hpf, PMN elastase >10,000 ng/ml)
Table 4. Inflammation marker and citric acid levels in patients with C. trachomatis prostate infection $(\mathrm{n}=8)$

\begin{tabular}{cccc}
\hline \multirow{2}{*}{$\begin{array}{c}\text { Patient with } \\
\begin{array}{c}\text { C. trachomatis } \\
\text { in EPS }\end{array}\end{array}$} & $\begin{array}{c}\text { EPS } \\
\text { PMN cells } \\
\text { per hpf }\end{array}$ & $\begin{array}{c}\text { PMN elastase } \\
\text { ng/ml }\end{array}$ & $\begin{array}{c}\text { citric acid } \\
\mathrm{mg} / \mathrm{ml}\end{array}$ \\
\hline 1 & $10-20$ & 4976 & 10.07 \\
2 & $10-20$ & $>10000$ & 12.95 \\
3 & $>30$ & $>10000$ & 2.17 \\
4 & $>30$ & 4463 & 6.43 \\
5 & $10-20$ & 357 & 13.09 \\
6 & $>30$ & $>10000$ & 5.36 \\
7 & $10-20$ & 4525 & 12.95 \\
8 & $>30$ & 6728 & 8.51 \\
\hline
\end{tabular}

and the decline in the concentration of citric acid in the prostatic fluid were the highest in the patients diagnosed with $C$. trachomatis infection (Table 4). Table 5 presents a comparison of the inflammation markers and the levels of citric acid between patients with and without $C$. trachomatis infection of the prostate gland. Statistical significance $(p=0.04)$ was found by Fisher's test only when a drop in citric acid in EPS was detected in the patients with chlamydial infection of the prostate gland and in the infection-free subjects. No statistical significance was revealed in the prostatic inflammation markers in both groups $(p>0.05)$. However, using the Mann-Whitney test, statistical significance of inflammation intensification in the infected and non-infected patients was noted (Table 6). Leukocyte count $(p=0.001)$, PMN elastase level $(p=0.0003)$, and citric acid level $(p=0.0001)$ in EPS were also statistically significant.

Analysis of the ROC curves for PMN elastase and citric acid showed that they have a likely role in the prognosis of chlamydial infection of the prostate gland. The area under the curve of the ROC for PMN elastase was 0.9063 and for citric acid 0.9342 . For a cut-off level of $>1795.9 \mathrm{ng} / \mathrm{ml}$ in the case of PMN elastase (sensitivity: $87.50 \%$, specificity: $89.47 \%$ ) and $<13.02$ $\mathrm{mg} / \mathrm{ml}$ in the case of citric acid (sensitivity: $87.50 \%$, specificity: $86.84 \%$ ) there is a great likelihood of C. trachomatis infection of the prostate gland (Figs. 1 and 2).

Table 3. Citric acid and PMN elastase concentrations in the EPS of chronic prostatitis patients $(n=46)$

\begin{tabular}{lcccc}
\hline \multirow{2}{*}{$\begin{array}{c}\text { Concentration } \\
\text { of citric acid }(\mathrm{mg} / \mathrm{ml})\end{array}$} & \multicolumn{2}{c}{ Concentration of PMN elastase $(\mathrm{ng} / \mathrm{ml})$} & \multirow{2}{*}{ Total } \\
\cline { 2 - 4 } & $\begin{array}{c}\text { normal } \\
(<250)\end{array}$ & $\begin{array}{c}\text { positive-intermediate } \\
(250-1000)\end{array}$ & $\begin{array}{c}\text { positive-high } \\
(>1000)\end{array}$ & \\
\hline Normal $^{*}$ & 6 & 6 & 4 & 16 \\
Low decrease $^{* *}$ & 4 & 14 & 4 & 22 \\
Intermediate decrease*** & 0 & 2 & 2 & 4 \\
High decrease*** & 0 & 0 & 4 & 4 \\
Total & 10 & 16 & 20 & 46 \\
\hline
\end{tabular}

* $>18.11 \mathrm{mg} / \mathrm{ml}$, ** $12.01-18.11 \mathrm{mg} / \mathrm{ml}$, *** $7.01-12.0 \mathrm{mg} / \mathrm{ml}, * * * *<7.0 \mathrm{mg} / \mathrm{ml}$. 
Table 5. Inflammation marker and citric acid levels in patients with and without $C$. trachomatis prostate infection

\begin{tabular}{llrrrc}
\hline \multirow{2}{*}{ EPS } & & \multicolumn{2}{c}{$\begin{array}{c}\text { C. trachomatis }(+) \\
\mathrm{n}=8\end{array}$} & \multicolumn{2}{c}{$\begin{array}{c}\text { C. trachomatis }(-) \\
\mathrm{n}=38\end{array}$} \\
\cline { 3 - 6 } & & $\mathrm{n}$ & $\%$ & $\mathrm{n}$ & $\%$ \\
\hline PMN cells per hpf & $<10(\mathrm{n}=12)$ & 0 & 0 & 12 & 47.4 \\
& $\geq 10(\mathrm{n}=34)$ & 8 & 100 & 26 & 52.6 \\
PMN-elastase $(\mathrm{ng} / \mathrm{ml})$ & $<250(\mathrm{n}=10)$ & 0 & 0 & 10 & 26.3 \\
& $\geq 250(\mathrm{n}=36)$ & 8 & 100 & 28 & 73.7 \\
Citric acid $(\mathrm{mg} / \mathrm{ml})$ & normal $(\mathrm{n}=16)$ & 0 & 0 & 15 & 39.5 \\
& decreased $(\mathrm{n}=30)$ & 8 & 100 & 23 & 60.5 \\
\hline
\end{tabular}

Table 6. Distribution of PMN elastase and citric acid levels in the EPS of patients with and without C. trachomatis prostate infection

\begin{tabular}{lcrrr}
\hline & \multicolumn{2}{c}{ PMN elastase } & \multicolumn{2}{c}{ Citric acid } \\
\cline { 2 - 5 } & \multicolumn{2}{c}{ C. trachomatis } & \multicolumn{2}{c}{ C. trachomatis } \\
& \multicolumn{1}{c}{$+(+)$} & $(-)$ & $(+)$ & $(-)$ \\
\hline Mean & 6381 & 1051 & 8.94 & 17.25 \\
Standard deviation & 3480 & 1682 & 4.07 & 4.36 \\
Lower quartile & 4479 & 182 & 5.63 & 14.20 \\
Median & 5852 & 467 & 9.29 & 16.76 \\
Upper quartile & 10000 & 1319 & 12.95 & 21.11 \\
\hline
\end{tabular}

\section{DISCUSSION}

The most common markers used to detect inflammation of the genitourinary tract, including prostatitis in men, are polymophonuclear leukocyte counts in urethral swabs, expressed prostatic secretions, semen, and urinary sediment $[18,21]$. The concentration of polymorphonuclear leukocyte enzymes, especially the level of PMN elastase, is a frequently used inflammation indicator [24]. In the current study we determined leukocyte counts and PMN elastase concentrations in the EPS of patients with chronic prostatitis (CP/CPPS and/or CBP).

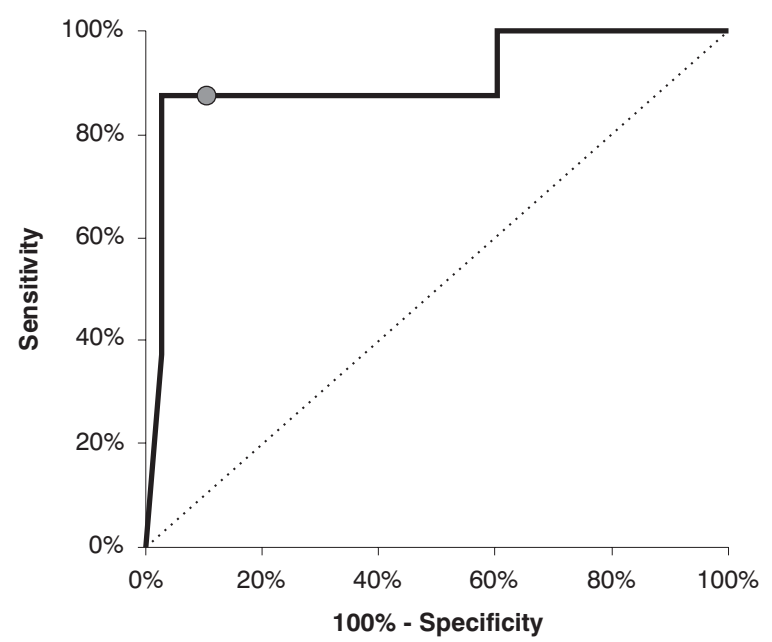

Fig. 1. Interactive diagram of a variable: PMN elastase. Cut-off: $>1795.90$, sensitivity: $87.50 \%$, specificity: $89.47 \%$.
A significant correlation was found between the two inflammation parameters in prostatic secretions. Most available literature data refer to granulocyte elastase concentration in the semen of patients with infertility [22, 23, 29]. Ludwig et al. evaluated PMN elastase concentration in the semen of chronic prostatitis patients [13]. We found no reports in the available literature on studies of PMN elastase concentration in EPS. Our results concerning PMN elastase level in EPS seem to be the first report regarding this problem. In the study material we found an increase in leukocyte count $(\geq 10$ per hpf) in the EPS in $73.9 \%$ and an increase in PMN

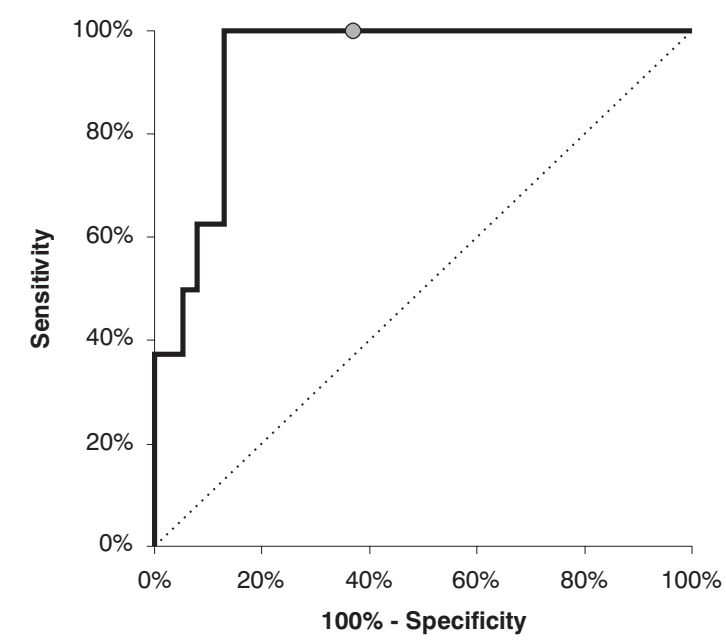

Fig. 2. Interactive diagram of a variable: citric acid. Cut-off: $>13.02$, sensitivity: $87.50 \%$, specificity: $86.84 \%$. 
elastase concentration in $78.3 \%$ of the patients with chronic prostatitis. We observed a high interdependence of both inflammation parameters $(87 \%)$. In four cases with high PMN elastase concentration, the leukocyte count was not elevated and in two patients the increased PMN cell count was not accompanied by a high elastase concentration. Similar interdependence was observed by Wolff and Anderson [22] and Eggert-Kruse et al. [5], both teams examining semen. Zorn et al. [29] indicated a better sensitivity of granulocyte elastase compared with leukocyte count as a genitourinary tract inflammation marker in men. Moreover, they accentuated the importance of PMN elastase as a parameter to detect latent genital infection in infertile men.

Citric acid is another parameter determined in our study indicating prostatic inflammation. With inflammation [10] or cancer of the prostate gland [2], the concentration of citric acid decreases. In the current study, a low citric acid concentration occurred in $65.2 \%$ of the men with chronic prostatitis. The drop in the level of citric acid significantly correlated with the increase in leukocyte count and the level of PMN elastase. Most of the patients with low citric acid concentrations had high PMN cell counts $(93.3 \%)$ and high granulocyte elastase concentrations $(86.7 \%)$ in EPS. Wolff's studies conducted on a group of infertile men with diagnosed leukocytospermia showed low citric acid concentrations in the semen [21]. This could indicate that latent prostatitis is responsible for leukocytes in the semen. In a review article, Zorn et al. [28] indicated a significant correlation between higher PMN elastase level and decreased citric acid concentration in infertile men's semen.

In our study group, $C$. trachomatis infection was found in $8 / 46(17.4 \%)$ of the men. In all the patients with chlamydial infection of the prostate we found a higher leukocyte count and PMN elastase and a decrease in citric acid concentration in EPS. This seems to suggest that $C$. trachomatis induces prostatitis, a notion many authors consider controversial. The highest values of the inflammation markers and the lowest of citric acid were observed in patients with $C$. trachomatis infection of the prostate. A statistically significant difference was noted in inflammation intensification between patients with and without chlamydial infection of the prostate gland. Wolff et al. [23] determined the correlation between $C$. trachomatis infection, the concentration of citric acid as an indicator of prostate function, and PMN elastase concentration in the semen of infertile men. None of the examined patients presented with genitourinary symptoms. The authors showed a significant increase in PMN elastase concentration and a decrease in citric acid concentration in patients with C. trachomatis infection compared with infection caused by other microorganisms, e.g. Ureaplasma urealyticum. Yoshida et al. [26] also observed higher PMN elastase concentrations in the semen of asymptomatic infertile patients with diagnosed C. trachomatis infection than in men infected with $U$. urealyticum and without infection. There are no literature data available concerning a cor- relation between $C$. trachomatis infection of the prostate gland and inflammation markers and citric acid in the prostatic fluid.

The current study is a continuation of research whose results were published earlier [17, 27]. In the study conducted in 2006 a relationship was found between $C$. trachomatis infection of the prostate gland and the level of citric acid in EPS [27]. Its continuation in 2007 demonstrated a correlation between the occurrence of anti-C. trachomatis antibodies in serum and prostatic secretions and the level of citric acid in the gland [17].

In conclusion, 1) the results showed a high interdependence between elevated leukocyte count and increased PMN elastase concentration in the prostatic fluid of patients with chronic prostatitis; 2) most patients with diagnosed prostatitis had decreased citric acid concentrations, which indicates impairment of the gland's function; 3) chlamydial prostatitis is accompanied by elevated inflammation markers and decreased citric acid concentration.

\section{REFERENCES}

1. Collins M. M., Stafford R. S., O’Leary M. P. and Barry M. J. (1998): How common is prostatitis? A national survey of physician visits. J. Urol., 159, 1224-1228.

2. Costello L. C. and Franklin R. B. (1998): Novel role of zinc in the regulation of prostate citrate metabolism and its implications in prostate cancer. Prostate, 35, 285-296.

3. Dan M., Samra Z., Siegel Y. I., Korczak D. and Lindner A. (1991): Isolation of Chlamydia trachomatis from prostatic tissue of patients undergoing transurethral prostatectomy. Infection, 19, 162-163.

4. Drach G. W., Meares E. M., Fair W. R. and Stamey T. A. (1987): Classification of benign diseases associated with prostatic pain: prostatitis or prostatodynia? J. Urol., 120, 266.

5. Eggert-Kruse W., Probst S., Rohr G., Aufenanger J. and Runnebaum B. (1995): Screening for subclinical inflammation in ejaculates. Fertil. Steril., 64, 1012-1022.

6. Fair W. R. and Cordonnier J. J. (1978): The pH of prostatic fluid: a reappraisal and therapeutic implications. J. Urol., 120, 695-698.

7. Frick J. and Aulitzky W. (1991): Physiology of the prostate. Infection, 19 (suppl. 3), 115-118.

8. Hennenfent B. R. and Feliciano A. E. (1998): Changes in white blood cell counts in men undergoing thrice-weekly prostatic massage, microbial diagnosis and antimicrobial therapy for genitourinary complaints. Br. J. Urol., 81, 370-376.

9. Jochum M., Pabst W. and Schill W. B. (1986): Granulocyte elastase as a sensitive diagnostic parameter of silent male genital tract inflammation. Andrologia, 18, 413-419.

10. Kammer H., Scheit K. H., Weidner W. and Cooper T. G. (1991): The evaluation of markers of prostatic function. Urol. Res., 19, 343-347.

11. Kavanagh J. P., Darby C. and Costello C. B. (1982): The response of seven prostatic fluid components to prostatic disease. Int. J. Androl., 5, 487-496.

12. Krieger J. N. and Riley D. E. (2002): Prostatitis: what is the role of infection. Int. J. Antimicrobiol. Agents, 19, 475-479. 
13. Ludwig M. (2003): Chronic prostatitis (chronic pelvic pain syndrome): seminal markers of inflammation. World J. Urol., 21, 82-85.

14. Ludwig M., Schroeder-Printzen I. Ludecke G. and Weidner W. (2000): Comparison of expressed prostatic secretions with urine after prostatitc massage - a means to diagnose chronic prostatitis/inflammatory chronic pelvic pain syndrome. Urology, 55, 175-177.

15. Nickel J. C., Nyberg L. M. and Hennenfent M. (1999): Research guidelines for chronic prostatitis: consensus report from the first national institutes of health international prostatitis collaborative network. Urology, 54, 229-233.

16. Ostaszewska I., Zdrodowska-Stefanow B., Badyda J., Puciło K., Trybuła J. and Bułhak V. (1998): Chlamydia trachomatis - probable cause of prostatitis. Int. J. STD AIDS, 9, 350-353.

17. Ostaszewska-Puchalska I., Zdrodowska-Stefanow B., Badyda J. and Galewska Z. (2007): Antichlamydial antibodies and citric acid in patients with chronic prostatitis. Arch. Immunol. Ther. Exp., 55, 57-60.

18. Weidner W. (1992): Prostatitis - diagnostic criteria, classification of patients and recommendations for therapeutic trials. Infection, 20 (suppl. 3), 227-231.

19. Weidner W., Diemer T., Huwe P., Rainer H. and Ludwig M. (2002): The role of Chlamydia trachomatis in prostatitis. Int. J. Antimicrobiol. Agents, 19, 466-470.

20. Weidner W. and Ludwig M (2003): Common organisms in urogenital infections with special impact on prostatitis. Eur. Urol., suppl. 2, 15-18.

21. Wolff H. (1995): The biologic significance of white blood cells in semen. Fertil. Steril., 63, 1143-1157.
22. Wolff H. and Anderson D. J. (1988): Evaluation of granulocyte elastase as a seminal plasma marker for leukocytospermia. Fertil. Steril., 50, 129-132.

23. Wolff H., Neubert U., Zebhauser M., Bezold G., Korting H. C. and Meurer M. (1991): Fertil. Steril., 55, 1017-1019.

24. Wolff H., Panhans A., Zebhauser M. and Meurer M. (1992): Chlamydia trachomatis induces an inflammatory response in the male genital tract and is associated with altered semen quality. Fertil. Steril., 58, 1260-1262.

25. World Health Organization (1992): WHO laboratory manual for the examination of human semen and sperm-cervical mucus interaction. 3rd Edition. The Press Syndicate University of Cambridge, Cambridge, pp. 72-73.

26. Yoshida K., Kobayashi N. and Negishi T. (1994): Chlamydia trachomatis infection in the semen of asymptomatic infertile men: detection of the antigen by in situ hybridization. Urol. Int., 53, 217-221.

27. Zdrodowska-Stefanow B., Ostaszewska-Puchalska I., Badyda J. and Galewska Z. (2006): The effect of Chlamydia trachomatis infection of the prostate gland on the concentration of citric amid. Arch. Immunol. Ther. Exp., 54, 69-73.

28. Zorn B., Sesek-Briski A., Osredkar J. and Meden-Vrotovec H. (2003): Semen polymorphonuclear neutrophil leukocyte elastase as a diagnostic and prognostic marker of genital tract inflammation - a review. Clin. Chem. Lab. Med., 41, 2-12.

29. Zorn B., Virant-Klun J. and Meden-Vrotovec H. (2003): Semen granulocyte elastase: its relevance for the diagnosis and prognosis of silent genital tract inflammation. Hum. Reprod., 15, 1978-1984. 